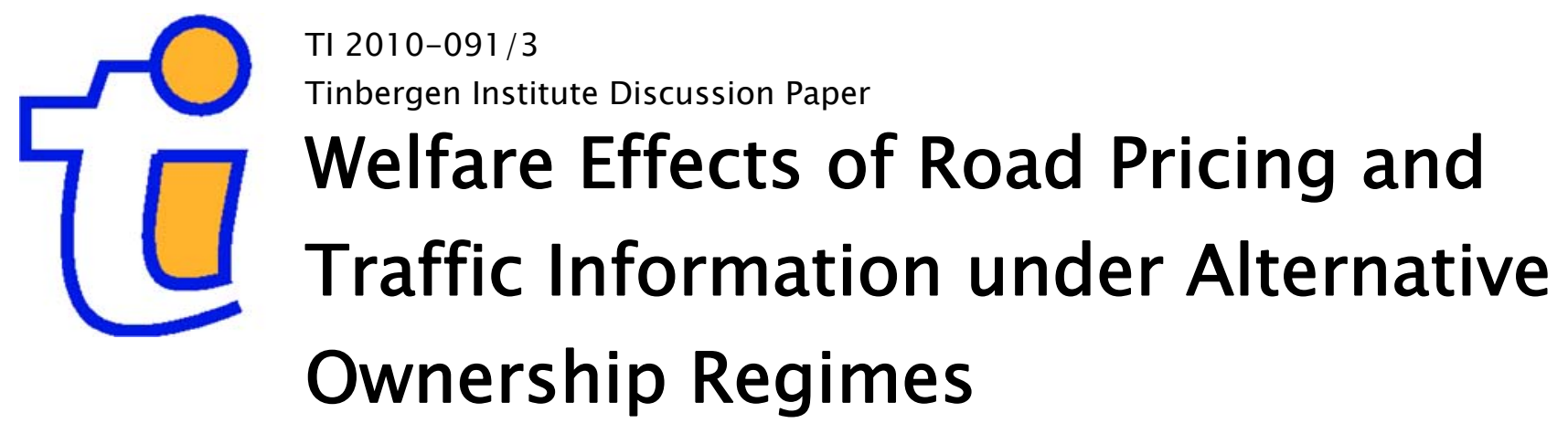

Sergejs Gubins*

Erik T. Verhoef:

Thomas de Graaff

VU University Amsterdam

* Tinbergen Institute 


\section{Tinbergen Institute}

The Tinbergen Institute is the institute for economic research of the Erasmus Universiteit Rotterdam, Universiteit van Amsterdam, and Vrije Universiteit Amsterdam.

Tinbergen Institute Amsterdam

Roetersstraat 31

1018 WB Amsterdam

The Netherlands

Tel.: +31(0)205513500

Fax: $+31(0) 205513555$

Tinbergen Institute Rotterdam

Burg. Oudlaan 50

3062 PA Rotterdam

The Netherlands

Tel.: + $31(0) 104088900$

Fax: $+31(0) 104089031$

Most TI discussion papers can be downloaded at http://www.tinbergen.nl. 


\title{
Welfare effects of road pricing and traffic information under alternative ownership regimes
}

\author{
Sergejs Gubins ${ }^{*}$, Erik T. Verhoef ${ }^{\text {a }}$, Thomas de Graaff \\ Department of Spatial Economics, VU University Amsterdam, the Netherlands
}

\begin{abstract}
This paper models strategic interactions between a product supplier, a provider of information about product quality, and end users, in the context of road transportation. Using a game-theoretical analysis of suppliers' pricing strategies, we assess the social welfare effects of traffic information under various road markets with different ownership regimes. The results show that in this context, the distortive welfare effect of monopolistic information pricing appears small to negligible. Collusion of the road operator and information provider yields higher social welfare than independent pricing by two firms. The intuition behind this result resembles that behind the welfare effects of double marginalization, but it is not exactly the same, as traffic information is not strictly complementary to road use.
\end{abstract}

JEL classification: $\quad$ L11, L15, R41, R48

Keywords: $\quad$ willingness to pay for information, private road operator, private information provider, ICT

\footnotetext{
${ }^{*}$ Corresponding author, e-mail address: sgubins@ feweb.vu.nl.

${ }^{a}$ Affiliated to the Tinbergen Institute, Amsterdam/Rotterdam, the Netherlands.

Financial support from The Netherlands Organization for Scientific Research (NWO) is gratefully acknowledged. This paper is part of TRISTAM project (Traveler Response and Information Service Technology - Analysis and Modeling). We thank for useful discussions and comments Falko Weiser, seminar participants at VU University Amsterdam and Tinbergen Institute.
} 


\section{Introduction}

Stochastic variation in product quality is common in many markets. Often the exact quality realization is unknown to buyers before the purchase. For instance, in a book or wine shop a buyer may not be perfectly aware of the quality of the product - a book could be interesting or not, bottles of wine could be good or not. Some consumers buy products anyway. Others execute a demand for numerous Internet blogs and specialized journals that advise audience on the "genuine" product value.

Transportation markets fit well into the above description. Due to the stochastic nature of travel, the exact travel time on a particular route in a network may be unknown to drivers a priori. That is, car accidents that block the street, bridge openings, weather conditions, etc., might slow down traffic in an unpredictable way. Information and telecommunication technologies (ICT) can then potentially support drivers with more reliable data on the duration of travel before the decision to make the trip is made.

The primary goal of this study is to assess the social welfare effects of the provision of information about product quality in the context of road transportation. Specifically, we show how the strategic behavior of market agents, depending on market ownership regimes, affects social welfare. We consider a game-theoretical setup of the market where a road operator, an information provider, and atomistic end users coexist. The information provider reports an actual quality value of a product, in our case that is the time necessary to make the trip. Conditional on the prices for road use and information, the rational consumers decide whether to travel or not, and whether to purchase information or not. A similar model could describe other markets with a supplier of a core product of variable quality, information supply and atomistic users.

We construct a simple model with elastic demand for and stochastic user costs of travel, and endogenous demand for traffic information. Depending on the price of information, the demand for travel might vary, thus affecting the possible profit and welfare of the road operation. In turn, an increase of a road toll forces more consumers to abstain from a trip, and hence limits the demand for information. Therefore, the information price affects the demand for travel and the price of travel affects the demand for information. The identification and welfare analysis of product/information price interdependence is a main contribution of this paper.

We study several related questions: Should the information be provided by a public or a private company? How does the expected number of trips change if a private information 
provider starts operating in the market? Should the road operator also own information provision, or is this bad for society? To answer these questions, we assess the effect of information provision by analyzing nine market forms with different ownership regimes, and compare the social welfare they generate.

Markets with limited information availability have since long been in the focus of economists (Stiglitz, 2000). The seminal paper by Stigler (1961) is the first attempt to outline the economic reasoning behind information acquisition. He uses the term "search" to describe a price survey conducted by buyers among sellers of a homogeneous product. He notes that the optimal amount of "search" might be computed by equating its marginal cost with its marginal benefit. Kihlstrom (1974) looks specifically at the demand for information about product quality. His model covers factors behind the demand for information of utility-maximizing consumers under a budget constraint. However, the exogeneity of the price of information leaves no room for strategic considerations of the market agents. Salop (1977) points out that a producer might discriminate buyers who are more efficient information-gatherers by means of price dispersion. In a similar way Kehoe (1996) links the level of consumers' uncertainty about the product quality to the product monopolistic price. But the markets they model lack a separate information provider, while in the case of quality dispersion that we consider in this paper, the cost of independent individual information collection is assumed to be prohibitively high for consumers.

The model by Lizzeri (1999), on the strategic behavior of a certification intermediary, looks at a market with an independent information firm that is hired by a supplier to truthfully testify the randomly assigned quality of a product to buyers. He demonstrates that the private information firm might have incentives not to disclose all information it possesses to the buyers in order to get a contract from a supplier. In his setup, an information provider is a Stackelberg leader. That precludes a feedback effect of the supplier's pricing behavior on the information provider's one. In our model we track Nash behavior. Besides, unlike Lizzeri (1999), we allow for an elastic product demand, which makes the set of possible pricing strategies more realistic. In our model, none of the agents can affect the quality of its performance, as we restrict our attention to the price dimension only. Thus, the information provider delivers the exact traffic information, while a road operator can not influence the traffic conditions of the road network.

We will assume that the core road supplier does not adjust the prices depending on the product quality. This is either because the supplier himself is unaware of the precise product 
quality on a specific day, or it may lack a fine pricing mechanism. This setup suits a road transport market well, as even if a road operator knows the traffic conditions, it might not be able to change a road toll accordingly. Travelers might dislike road toll variations, and to make a road pricing acceptable, the road operator might be constrained to a fix toll. ${ }^{1}$

Advanced Traveler Information Systems (ATIS) is a concrete example of ICT implementation in transportation. Papers by Emmerink et al. (1996), Verhoef et al. (1996), de Palma and Lindsey (1998), Yang (1999), Zhang and Verhoef (2006), and Fernandez et al. (2009) investigate the effect of free of charge ATIS on drivers' decision to travel. They appraise efficiency inputs of information when road pricing is or is not in place. These papers allow for negative external effects of individual travel, i.e. congestion. Often, indeed, negative congestion externalities are taken into account in the transportation literature. Given our primary focus on strategic interactions between suppliers, we assume that the road network is uncongestible. Theoretically, both public and private providers internalize the negative externalities into the road toll (Small and Verhoef, 2007). The difference between the pricing rules is that the latter would impose a demand-related mark-up, which increases if demand becomes less elastic. By setting the external marginal cost to zero, we still preserve the monopolistic mark-up on top of the first-best charge in the model, so the main difference between private and public supply is maintained in our analysis. But the feedback effects on congestion levels are ignored.

Emmerink et al. (1998) explicitly derive the demand for information from the elastic travel demand. We follow their approach in the set-up of the model and extend it by considering pricing behavior of the road operator and information provider. Zhang and Verhoef (2006) show the effect of monopolistic traffic information on welfare for a one-link toll-free road network. This paper, to the best of our knowledge, is the first to consider a multiple-link market with an elastic travel demand, and independent road and information suppliers.

\footnotetext{
${ }^{1}$ More generally, if the price reveals the exact quality, traffic information is relevant only when the road toll is not yet known on the moment the route is chosen, or travelers respond to the expected road price only. Our analysis may be taken to consider an undifferentiated toll, or the expected value of a differentiated toll, the value of which is known by the travelers only after the route is chosen.
} 


\section{Model}

\subsection{Travel demand and supply}

We consider a road network of $n \geq 2$ parallel routes connecting one origin and one destination. Drivers are willing to make a trip if the benefits of it are at least equal to the costs, otherwise they stay home (or use alternative transport not explicitly modeled). We impose a linear inverse demand function for travel of the form $D^{T}=d-a N$, where $N$ is the number of

drivers. A driver's $j$ individual travel benefit is $D_{j}^{T}=d-a N_{j}$, where $N_{j}$ is the number of drivers with the higher travel benefit than driver $j$.

The cost of the trip without delays $C^{0}$ is constant and includes car depreciation, fuel and time costs. This cost function choice has several implications. First, there are no externality effects in the network. Second, it implies that we assume that people are homogenous with respect to value of time. Finally, all routes are identical in terms of expected generalized costs. This is required for parallel routes to attract travelers both with and without information.

Possible delays due to, for instance, road accidents blocking the way or other incidents, make the travel cost stochastic. With probability $p$ the cost of the trip increases from $C^{0}$ to $C^{1}$. The probability of simultaneous incidents occurring on all $n$ roads is $p^{n}$. Drivers are perfectly aware of the possible cost levels and the probability associated with them, and rationally estimate expected travel cost as $E(C)=C^{0}(1-p)+C^{1} p$ when being uninformed.

The road operator, which may be either welfare or profit maximizing, owns the whole network and takes its structure as given. Assuming no deterioration of the roads, the operator's marginal cost is zero. Using this static setup, we will next derive drivers' willingness to pay for information in the next subsection.

\subsection{Demand for information}

Traffic information is the information about the costs of travel. While still at home, the driver gets access to perfectly reliable information and observes what the costs of travel on each of the $n$ routes are. Afterwards, the driver chooses whether to travel and if so, which route to take. If at least on one of the routes the cost of travel is lower than the benefit, the driver makes a trip on such a route. If the cost on all routes is higher, the driver abstains from a trip. We assume no incident can happen on the way - i.e., all information is accurate. Our key interest in this section lies in how much drivers are willing to pay for information. 
Figure 1a. Demand and stochastic costs of travel

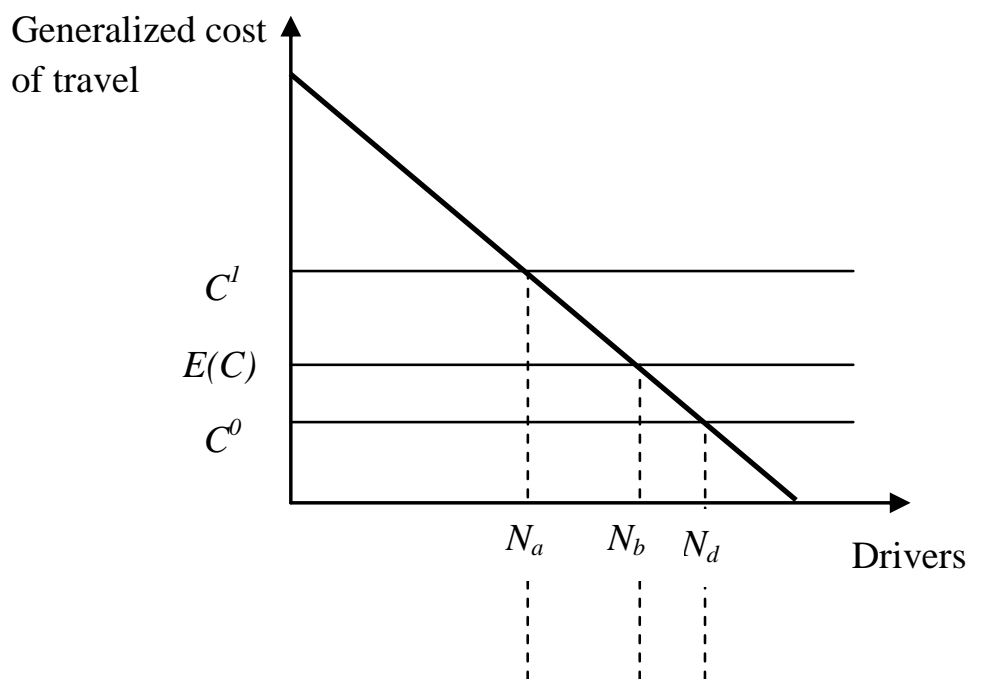

Figure 1b. Willingness to pay for information

Figure 1c. Demand for information

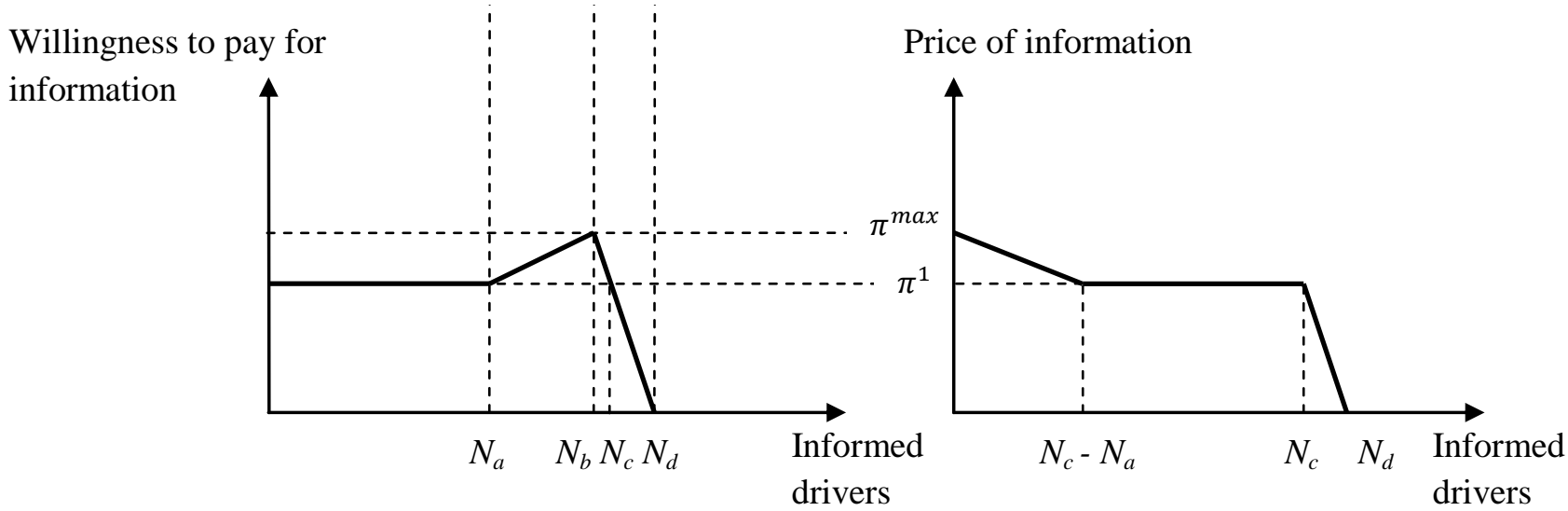

The willingness to pay for information of driver $j$ (hereafter $w t p_{j}^{I}$ ) is the difference between the expected consumer surpluses for informed and uninformed traveling. When traffic information is not available, driver $j$ compares the expected $\operatorname{cost} E(C)$ with her benefit of traveling $D_{j}^{T}$, and then decides whether to travel or not. In the case when information is available, the expected consumer surplus depends on the relative strength of the benefit $D_{j}^{T}$ in comparison to costs $C^{0}, E(C)$ and $C^{1}$, in a way to be explained below. ${ }^{2}$ Due to the assumed linearity of the travel demand, it results in a piecewise linear function of willingness to pay for information.

\footnotetext{
${ }^{2}$ One might also consider the cost of uncertainty, i.e. the cost of not knowing what the actual cost of the trip will be. It manifests itself in a psychological discomfort of a drive, in an inability to schedule the agenda properly and so on. The cost of uncertainty might be the part of generalized cost of travel only for uninformed travelers. For informed drivers the cost of uncertainty is zero. Inclusion of homogeneous value of uncertainty across people does not affect
} 
To understand the shape of the function of the willingness to pay for information, we first examine the section of the travel demand where $D_{j}^{T} \geq C^{1}$. No matter what the costs are, drivers with benefits higher or equal to $C^{1}$ are always willing to travel, either with or without information. Of course, they prefer to incur the lowest cost possible, so they use information to make a better route choice to avoid delays. When informed, they face a $\operatorname{cost} C^{0}$ in a fraction $1-p^{n}$ of the cases, compared to $1-p$ when uninformed. Thus, the expected cost of informed trip is $\left(C^{0}+\pi\right)\left(1-p^{n}\right)+\left(C^{1}+\pi\right) p^{n}$, where $\pi$ is the price of information. The maximum price that driver $j$ is willing to pay for information, $w t p_{j}^{I}$, conditional on her travel benefit $D_{j}^{T} \geq C^{1}$, is:

$w t p_{j}^{I}=\left(C^{1}-C^{0}\right)\left(p-p^{n}\right)$

Note that $w t p_{j}^{I}$ does not depend on individual willingness to pay for travel, $D_{j}^{T}$. The benefit of information in this case is solely a route choice benefit, which is a function of the cost of a delay $C^{1}-C^{0}$, and the rate at which information helps avoid this delay, $p-p^{n}$. Besides, the expected number of trips is the same both with and without information, as drivers are always willing to travel irrespective of the travel cost.

Next, consider the segment of the travel demand where $C^{1}>D_{j}^{T} \geq E(C)$. Without information drivers always make the trip, although in a fraction $p$ of the cases they face $\operatorname{cost} C^{1}$, which is higher than their benefit $D_{j}^{T}$. Nevertheless, in terms of expected consumer surplus, travel does pay off. With information, drivers abstain from travelling in a fraction $p^{n}$ of the cases. The lower their travel benefit, the higher this information benefit is, as the drivers save more. Thus, on top of a "route choice benefit", defined by equation (1), there is a "participation benefit". A participation benefit is the benefit one gets by changing the decision of whether to make a trip or not. In contrast to the route choice benefit, the participation benefit depends on $D_{j}^{T}$. The expected consumer surplus is $\left(D_{j}^{T}-C^{0}\right)\left(1-p^{n}\right)-\pi$. The willingness to pay for information of driver $j$, conditional on demand $C^{1}>D_{j}^{T} \geq E(C)$, is:

the results substantially. For the clarity of exposition we omit it. De Palma and Picard (2008) explicitly include heterogeneous risk-aversion into the evaluation of information value. 
$w t p_{j}^{I}=p\left(C^{1}-C^{0}\right)-p^{n}\left(d-C^{0}\right)+a N_{j} p^{n}$

For this segment of travel demand, $w t p_{j}^{I}$ is increasing with decrease of $D_{j}^{T}$, because the participation benefit increases as $D_{j}^{T}$ becomes smaller. The expected number of trips with information is always lower than without information, because informed drivers do not participate in a fraction $p^{n}$ of the cases.

Now, we look at the third part of the travel demand where $E(C)>D_{j}^{T} \geq C^{0}$. These drivers do not travel without information, as the expected cost exceeds the benefit. However, information makes it beneficial to travel in a fraction 1- $p^{n}$ of the cases. The expected cost and benefit are the same as in the case before. So, $w t p_{j}^{I}$, conditional on demand $E(C)>D_{j}^{T} \geq C^{0}$, is:

$w t p_{j}^{I}=\left(d-C^{0}\right)\left(1-p^{n}\right)-a N_{j}\left(1-p^{n}\right)$

Here $w t p_{j}^{I}$ is decreasing with a decline of $D_{j}^{T}$, because the participation benefit decreases. The expected number of trips with information is always higher than without information (when it is zero).

The last part of the demand function, where $C^{0}>D_{j}^{T}$, is not relevant for our discussion, as these drivers will never travel and traffic information is of no use for them.

Figure 1a shows the original demand and supply setup, while Figure 1b illustrates the result of the derivation of $w t p^{I}$ just discussed. The drivers between $N_{a}$ and $N_{b}$ gain both a route choice and participation benefit of information, with driver $N_{b}$ having the highest $w t p_{j}^{I}$, as she obtains the maximum participation benefit. Drivers to the left-hand side of $N_{a}$ enjoy a route choice benefit as given by (1). Drivers to the right-hand of $N_{b}$ have a participation benefit only.

Figure $1 \mathrm{~b}$ shows $w t p_{j}^{I}$ for each driver, ordered according to the inverse demand curve from Figure 1a. However, the inverse demand function for information represents the relationship between the price of information $\pi$ and the number of drivers willing to be informed $N^{I}$. Note that for the price $\pi^{\max }$, which corresponds to the highest $w t p_{j}^{I}$, there is only one person, namely $N_{b}$, willing to acquire information. By changing the order of individuals we transform Figure 1b into 1c, the latter being the conventional inverse demand function for 
information. Using expressions (1), (2) and (3) we derive this inverse demand for information, $D^{I}$, of the following form:

$D^{I}=\left\{\begin{array}{c}\left(\left(p-p^{n+1}\right)\left(C^{1}-C^{0}\right)-N^{I} a\left(1-p^{n}\right) p^{n} \mid N^{I} \in\left(0 ; N_{c}-N_{a}\right)\right) \\ \left(\left(C^{1}-C^{0}\right)\left(p-p^{n}\right) \mid N^{I} \in\left[N_{c}-N_{a} ; N_{c}\right]\right) \\ \left(\left(1-p^{n}\right)\left(d-C^{0}\right)-N^{I} a\left(1-p^{n}\right) \mid N^{I} \in\left(N_{c} ; N_{d}\right]\right)\end{array}\right.$

\section{Pricing}

\subsection{Independent pricing}

In this subsection we consider for both suppliers (i.e., the road operator and the information provider) private profit-maximizing and public welfare-maximizing pricing. In the next subsubsection we look at monopolistic information pricing when the road network is tollfree. Then, we consider a road operator's price when information is available free of charge. Subsection 3.2 focuses on the interdependence of the pricing behavior of profit-maximizing firms. Subsection 3.3 derives the welfare-maximizing pricing strategies.

\subsubsection{Information pricing}

An information provider sets either the welfare or the profit maximizing price of information. Figure 2 shows the demand for and the marginal revenue (hereafter $m r$ ) of information. For simplicity we set the marginal cost (hereafter $m c$ ) of information provision at zero. It is plausible that also in reality, given available technologies, after substantial fixed and/or sunk costs investments, the distribution of information to individual drivers is virtually costless. One might think of a subscription to a digital service. Moreover, below we show that the introduction of a positive $m c$ does not affect the further analysis fundamentally, as long as it is sufficiently low.

The kinked information demand function derived in the previous section implies a kinked and discontinuous marginal revenue function for information. Let $\bar{\pi}$ be the price level of the first kink of the $m r$ function. As long as $m c<\bar{\pi}$, the only intersection of $m r$ and $m c$ corresponds to the $N_{c}$ level of demand, as it is easy to show that $\bar{\pi}=\left(C^{1}-C^{0}\right)\left(p+p^{n+1}-2 p^{n}\right)$ is always 
Figure 2. Demand for (bold line) and marginal revenue (dash line) of information

Price and marginal revenue of information

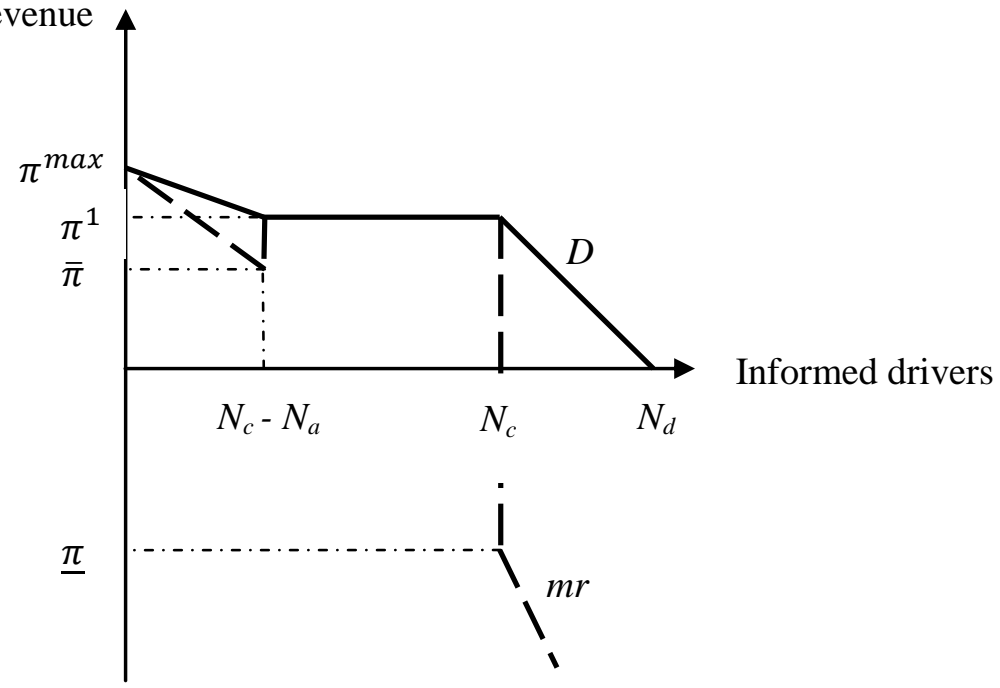

positive. $^{3}$ That results in a profit-maximizing price $\pi^{1}$, equal to the route choice benefit. A welfare-maximizing information provider, in contrast, would set the price to zero, the marginal cost.

Interestingly, the introduction of the information with a price $\pi=\pi^{1}$ does not change the expected number of trips made in the network (this holds for $\pi>\pi^{1}$ as well). It is easy to prove that the decrease in the number of expected trips by the drivers between $N_{a}$ and $N_{b}$ (see Figure 1b) is exactly offset by an increase in the number of expected trips by the drivers between $N_{b}$ and $N_{c}{ }^{4}{ }^{4}$ The first $N_{a}$ drivers keep their overall number of trips constant. This exact insensitivity of the expected number of trips depends on the assumed linearity of travel demand.

\subsubsection{Road pricing}

In absence of wear and tear or any other marginal cost, the welfare maximizing road operator lets every driver use the road network without a charge, so that $\tau=m c=0$. That holds true both when information is not available and when its price is zero. The objective of the

\footnotetext{
${ }^{3}$ It is also possible that the intercept of the $m c$ and $m r$ is to the right of $N_{c}$, i.e. a price level of the last kink of the $m r$ function, $\underline{\pi}$, is positive $\left(\underline{\pi}=2\left(\mathrm{C}^{1}-\mathrm{C}^{0}\right)\left(\mathrm{p}-\mathrm{p}^{\mathrm{n}}\right)-\left(\mathrm{d}-\mathrm{C}^{0}\right)\left(1-\mathrm{p}^{\mathrm{n}}\right)\right)$. However, the necessary condition for $\underline{\pi}$ to be positive is $2 p-p^{n}>1$, which might hold only when $p>0.5$ and $n>2$. For any practical purpose a probability of an incident on one route larger than 50 percent is hardly realistic, so we do not consider it in the analysis.

${ }^{4}$ Using equations (2) and (3), one can show that the road use declines by $\frac{\pi^{m a x}-\pi^{1}}{a}$ for all drivers to the left from $N_{b}$ if the information price drops from $\pi^{\max }$ to $\pi^{1}$. For all drivers to the right from $N_{b}$ the road use increases by exactly the same amount.
} 
Figure 3. A road operator profits under various tolls with free information

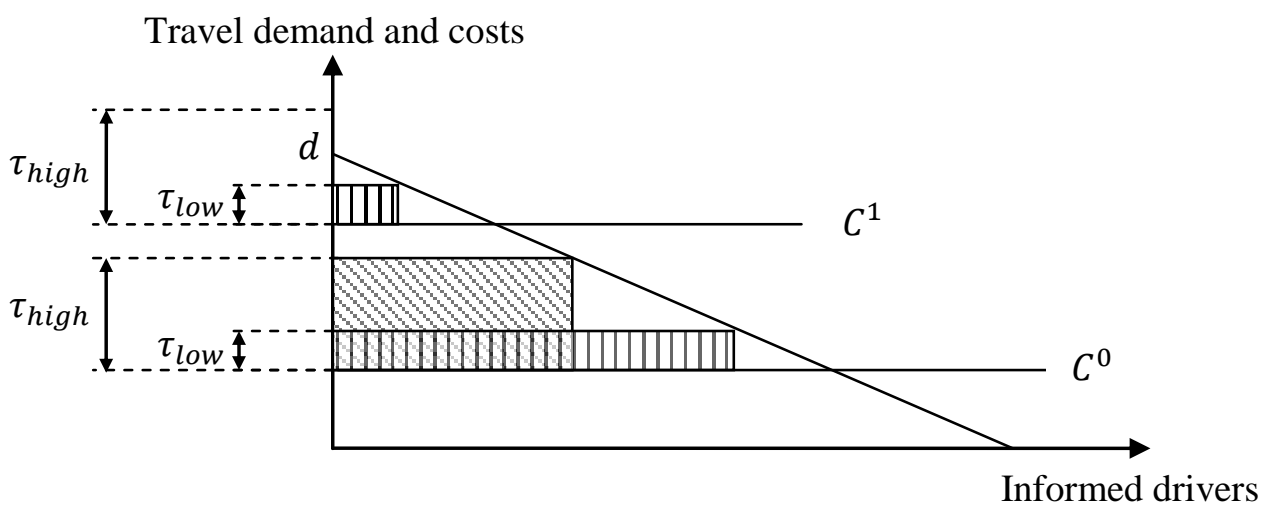

profit-maximizing firm is to price the road use in a way that maximizes its profit function $\Pi(\tau)$. When traffic information is not available to the drivers, the operator sets a road toll $\tau=\frac{d-E(C)}{2}$.

If free information is available to the drivers, the profit function of the road operator might fail to be quasi-concave. As this complicates deriving an analytical solution for the profitmaximizing road toll, we will run numerical simulations. First we give the intuition behind this point.

The road operator faces two pricing options, one of which is characterized by a zero road use in the high-cost state. A low road toll $\tau_{\text {low }} \leq d-C^{1}$ insures that the drivers with a high willingness to pay for travel (i.e. $D_{j}^{T} \geq C^{1}+\tau$ ) would always travel, while others travel in a fraction $1-p^{n}$ of the cases. A high toll $d-C^{1}<\tau_{\text {high }} \leq d-C^{0}$, implies that there are only travelers driving in a fraction $1-p^{n}$ of the cases. Figure 3 illustrates these two alternatives, the shaded areas representing road operator profits. Depending on the exact specifications of $D^{T}, C^{1}, C^{0}, p$ the firm will prefer either the profit under toll $\tau_{l o w}$ or that under toll $\tau_{\text {high }}$. Assume that probability $p$ is 50 percent, so that the shaded areas under $\tau_{\text {low }}$ are equally weighted. Then, as Figure 3 suggests, a road toll $\tau_{\text {high }}$ yields the highest profit. However, if the $\operatorname{cost} C^{0}$ would be higher or if $D^{T}$ would be steeper, then the road toll $\tau_{\text {low }}$ might results in a higher profit.

Figure 4 shows a hypothetical profit function that is not quasi-concave. Here, a road toll $\tau_{\text {low }} \leq d-C^{1}$ creates the highest profit. To identify the profit-maximizing road toll for a profit function that is not quasi-concave, one should check all stationary points and all corner solutions (Wolfstetter, 1999, p.13). 
Figure 4. A hypothetical road operator profit function $\Pi(\tau)$ with free information

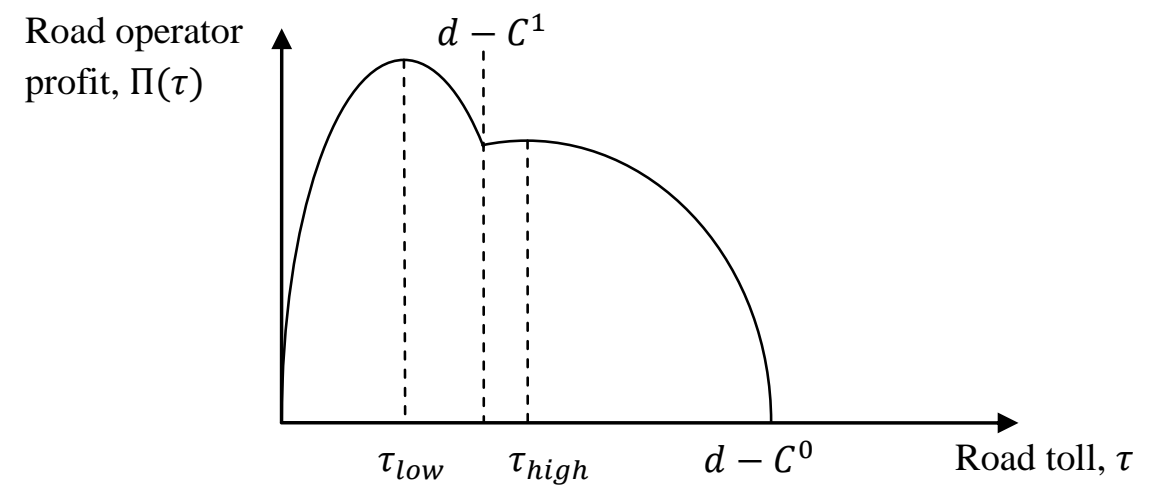

\subsection{Interdependence of information and road pricing}

In the previous two subsubsections we considered information and road pricing independently from one another. A closed-form solution exists for the profit-maximizing information price $\pi$, and a road operator was found to check for the profit-maximizing price $\tau$ in the set of local maxima and corner solutions. In both cases, the price of the other service was assumed to be equal to zero. Now we examine how the inclusion of the positive road toll affects the optimal price of information and vice versa. Effectively, we estimate the reaction functions, also known as best-response, of a private road operator and a private information provider. The reaction function of an information provider is a profit-maximizing price $\pi$ as a function of a $\operatorname{road}$ price $\tau$, and the other way around for the road operator.

\subsubsection{Reaction function of the information provider}

We start with the calculation of the information provider's reaction function (see Figure 5). We let some part of the inverse travel demand exceed the highest costs when the road toll is zero, i.e. $d \geq C^{1}$. As shown above, if the road toll is zero, the firm optimal price of information is always $\pi^{1}$ (given the reservations made in footnote 2 ).

When increasing the road toll by $\tau \leq d-C^{1}, N_{a}$ in Figure $1 \mathrm{~b}$ shifts left. The number of drivers to the right-hand side of $N_{a}$ stays the same, although these are now different people, i.e., they have a different willingness to pay for travel. The constancy of $N_{d}-N_{a}$ is due to the assumed linearity of the travel demand. The shape of the information demand remains unchanged, apart from the horizontal segment being reduced. As long as there are some drivers 
Figure 5. Reaction function of the information provider

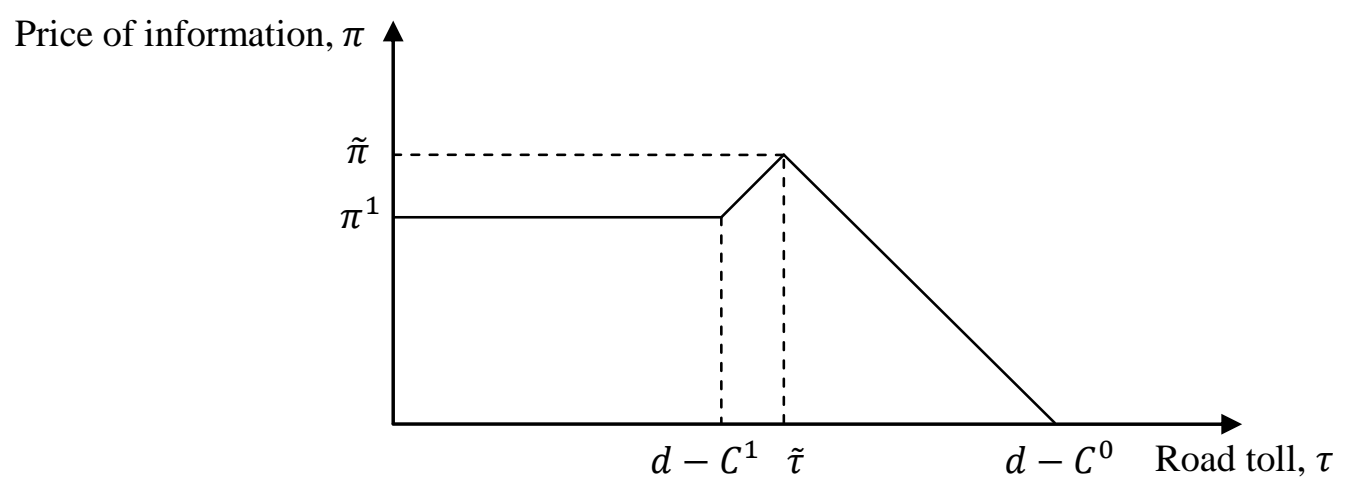

willing to travel in both states of nature, an information provider finds it most profitable to set the price equal to the route choice benefit $\pi^{1}$. Thus, the profit-maximizing information price is constant, given $\tau \leq d-C^{1}$.

When the road toll is so high that no informed driver travels always, the information provider has an incentive to increase $\pi$. An increase of the road toll reduces the amount of drivers, but those drivers who still travel have a relatively high participation benefit. That is due to the increasing cost of possible travel when there are delays on all routes, $C^{1}+\tau$. In these circumstances, information becomes more valuable, as it helps to avoid the costs of an unbeneficial trip. That makes it appealing for the information firm to increase $\pi$. Hence, the reaction function in Figure 5 slopes upward beyond $d-C^{1}$.

Figure 6a illustrates how an increase of a road toll from $\tau=d-C^{1}$ to $\tau=\tilde{\tau}$ (to be defined below) shifts the willingness to pay for information function leftward. The order of the road users in Figure 6a corresponds to the order of drivers in the demand for travel. Figure $6 \mathrm{~b}$ reorders those users, by $w t p_{j}^{i}$, to depict the inverse demand function for information.

The higher the road toll, the smaller the number of drivers with both a route choice and participation benefit of information. Technically, after reaching the toll $\tilde{\tau}$ (see below), the level of the second kink of $m r$ function $\underline{\pi}$ becomes positive (see Figure $6 \mathrm{~b}$ ). From this point onward, a profit-maximizing information price declines with the road toll, to capture consumer surplus of drivers who have only a participation benefit. Thus, the reaction function kinks for the second time. Figures $6 \mathrm{a}$ and $6 \mathrm{~b}$ show the way a raise of the road toll from $\tau=d-C^{1}$ to $\tilde{\tau}$ increases information price from $\pi^{1}$ to $\tilde{\pi}$, where $\tilde{\tau}$ and $\tilde{\pi}$ are:

$\tilde{\tau}=d-C^{0}-\frac{2 p\left(C^{1}-C^{0}\right)}{1+p^{n}}$ 
$\tilde{\pi}=\frac{\left(C^{1}-C^{0}\right)\left(p-p^{n+1}\right)}{1+p^{n}}=\frac{\pi^{\max }}{1+p^{n}}$

Those values are derived by using information demand equation (4) and calculating $m r$ functions when $\underline{\pi}=0$. The kinked shape of the information provider's reaction function depicts an interesting relationship between $\pi$ and $\tau$. For some of a road toll, $\tau \in\left[0, d-C^{1}\right]$, the information price is strategically neutral. For a short range, $\tau \in\left(d-C^{1}, \tilde{\tau}\right]$, it is a strategic complement; and for the rest, $\tau \in\left(\tilde{\tau}, d-C^{0}\right]$, it is a strategic substitute.

Figure 6a. Willingness to pay for information when $\tau=d-C^{1}$ (regular line) and when $\tau=$ $\tilde{\tau}$ (bold line)
Figure 6b. Demand (solid lines) and $m r$ (dashed lines) for information when $\tau=d-$ $C^{1}$ (regular line) and when $\tau=\tilde{\tau}$ (bold line)

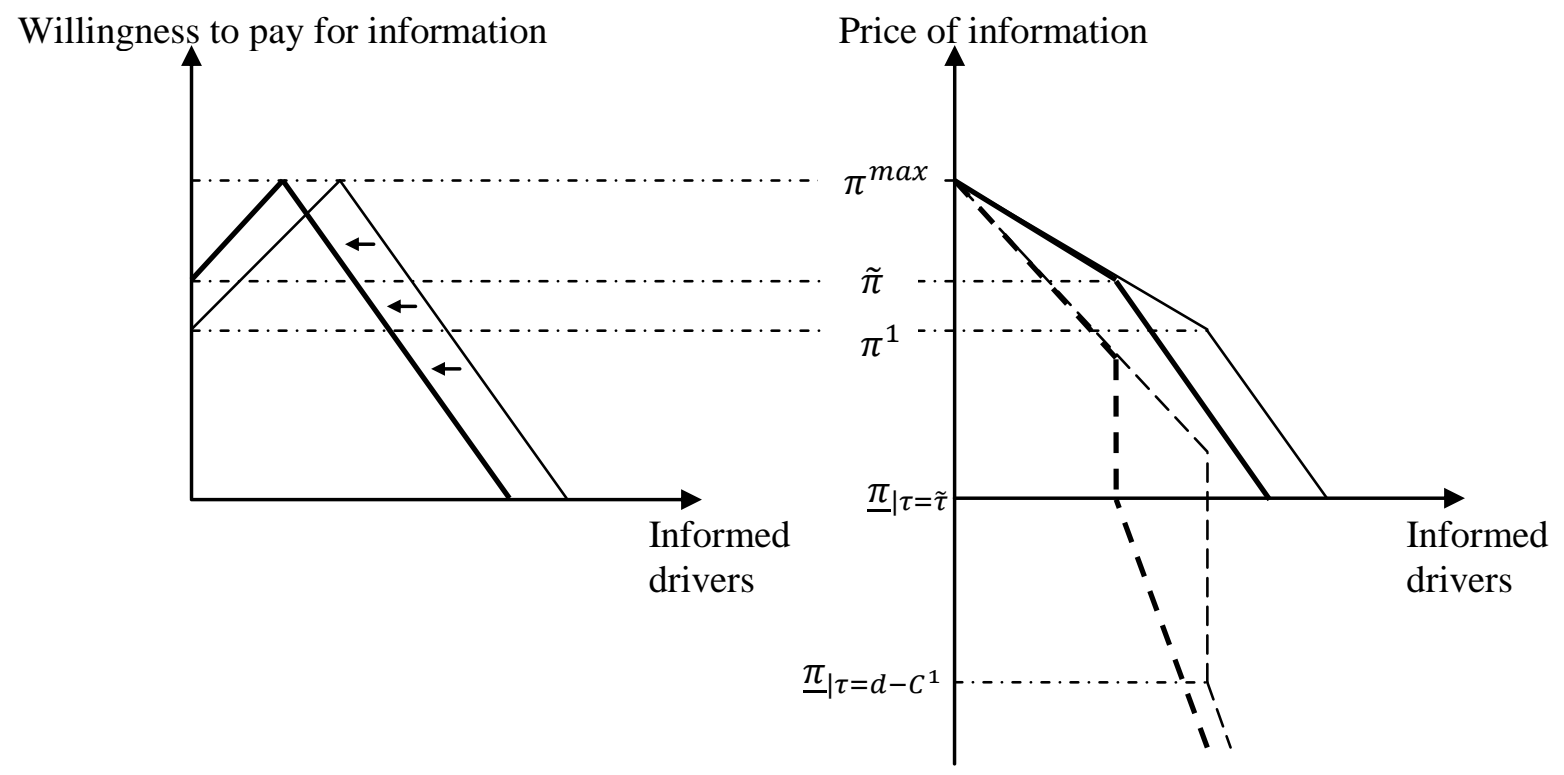

\subsubsection{Reaction function of the road operator}

It is somewhat more involved to identify the reaction function of a road operator, as it does not have a single closed-form solution. Nevertheless, one might distinguish two relevant closed-form solutions. Here we briefly outline them, and provide the intuition behind their main characteristics. 
As already discussed in the previous section, a road operator considers two possible alternatives for a profit-maximizing road toll $\tau$ : a relatively low road toll, $\tau_{\text {low }} \leq d-C^{1}$, and a higher toll, $d-C^{1}<\tau_{\text {high }} \leq d-C^{0}$. The resulting profits can be composed numerically.

First, focus on the low road toll $\tau_{\text {low }} \leq d-C^{1}$. Think of an extreme case when the price of information is prohibitively high, i.e. $\pi>\pi^{\max }$. Since there are no drivers willing to acquire expensive information, the profit function of the road operator has the following form:

$\Pi_{R}=\tau \frac{d-E(C)-\tau}{a}$

Note that this is identical, not surprisingly, to the profit function under the no information regime.

Next, imagine that the information price drops to the level $\pi^{\max } \geq \pi>\pi^{1}$, with $\pi^{1}$ equal to the route choice benefit. Now there are drivers who find it attractive to buy information. However, with a linear travel demand, it is easy to show that the expected number of trips will stay unchanged. Some drivers who did not travel without information will now travel in a fraction $1-p^{n}$ of the cases. Some drivers who traveled without information will now stay home in a fraction $p^{n}$ of the cases. The numbers of drivers involved in these two categories have a ratio $p^{n} /\left(1-p^{n}\right)$, as can be seen from equations (2) and (3). Overall, the amount of newly generated trips will, therefore, be exactly the same as the number of abstained trips.

Information provision under price $\pi^{\max } \geq \pi>\pi^{1}$ will increase the consumer surplus of informed drivers by $w t p_{j}^{I}-\pi$. However, a road operator is unable to skim off a part of the additional consumer surplus into a profit, as that would imply an increase of the road toll above $d-C^{1}$. As the expected number of trips is the same, one can show that the profit function, as given by equation (5), is not affected by the decrease of $\pi$.

At the price level $\pi^{1}$, those drivers with high travel demand $D^{T} \geq C^{1}+\tau$ will purchase the information to get a route choice benefit. Nevertheless, their acquaintance with information does not affect the road operator's profit, as these drivers do not change their travel decisions, since they always travel. At the price $\pi^{1}$ these newly informed drivers do not obtain a higher consumer surplus. As long as $\pi \geq \pi^{1}$, the road operator's profit function does not depend on the information price, given $\tau_{\text {low }} \leq d-C^{1}$. 
Figure 7. Possible reaction functions of an information provider and a road operator

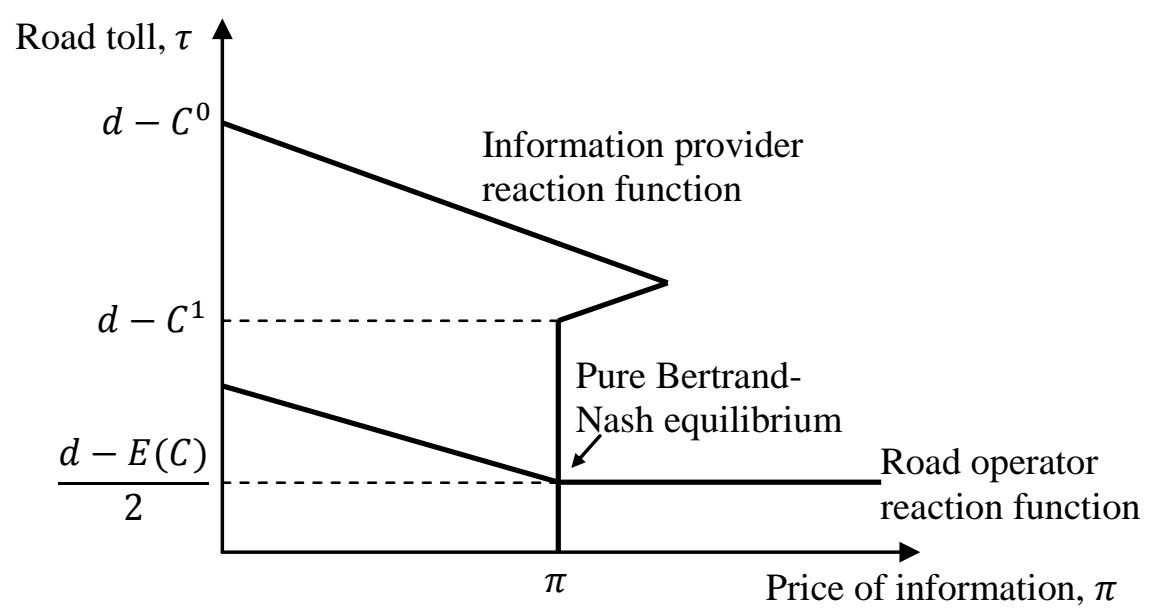

However, a further decrease of the information price, so that $\pi<\pi^{1}$, prompts a change and the road operator's reaction function kinks (see Figure 7). Drivers who previously did not travel (to the right of $N_{C}$ in Figure 1b) will start buying information and will now travel in a fraction $1-p^{n}$ of the cases. Already informed drivers will gain a larger consumer surplus from a route choice benefit, exceeding $\pi$, which a road operator is now able to internalize. The profit function of the road operator $\Pi_{R}(\tau)$, conditional on the toll $\tau_{\text {low }} \leq d-C^{1}$ and $\pi \leq \pi^{1}$, is:

$\Pi_{R}=\tau_{\text {low }} \cdot\left(\frac{d-C^{0}-\tau_{\text {low }}}{a}-\frac{p^{n}\left(C^{1}-C^{0}\right)}{a}-\frac{\pi}{a}\right)$

Note that the second term on the right hand side of the equation (6) is the amount of trips the drivers make when the price of information and the road toll are low. $\frac{d-C^{0}-\tau_{\text {low }}}{a}$ is the number of drivers willing to travel in low-cost state when the price of information is zero. $\frac{\mathrm{p}^{\mathrm{n}}\left(\mathrm{C}^{1}-\mathrm{C}^{0}\right)}{\mathrm{a}}$ is the number of trips which drivers will abstain from in a fraction $p^{n}$ of all cases. $\frac{\pi}{\mathrm{a}}$ is a number of drivers who will not be present in the market with a positive information price, compared to free information case. The profit-maximizing road toll for the profit function (6) is $\tau=\frac{d-C^{0}-p^{n}\left(C^{1}-C^{0}\right)-\pi}{2}$. As the price of information goes down, the road toll rises to capture the growing consumer surplus. 
The reaction function of a road operator will look like the one depicted in Figure 7. This figure shows the reaction functions of both a road operator and an information provider, where the intersection is a pure Nash equilibrium. This pure Nash equilibrium is a stable trembling hand perfect one, because a small deviations from equilibrium, e.g. by mistake, would induce the agents to return to the equilibrium prices.

Several outcomes of this Nash equilibrium follow immediately. First, as discussed before, the number of expected trips in the network under the no information regime and with profitmaximizing road pricing is the same as under the Nash equilibrium. Second, the road toll and hence the profit of the road operator is the same as it is without information. Third, the drivers with high willingness to pay for travel $D^{T} \geq C^{1}$ do not gain additional consumer surplus from the introduction of information, as the route choice benefit is exactly skimmed off by the information provider.

Note that the set of reaction functions depicted in Figure 7 is only one of the possible alternatives. It assumes that $\Pi_{R}\left(\tau_{\text {low }}\right)>\Pi_{R}\left(\tau_{\text {high }}\right)$, though this does not need to be true over the entire range of $\tau$. Figure 8 shows another possible reaction function of the road operator. Whilst the resulting equilibrium is identical to the one discussed above, the properties of the function are

Figure 8. Possible reaction functions of an information provider and a road operator

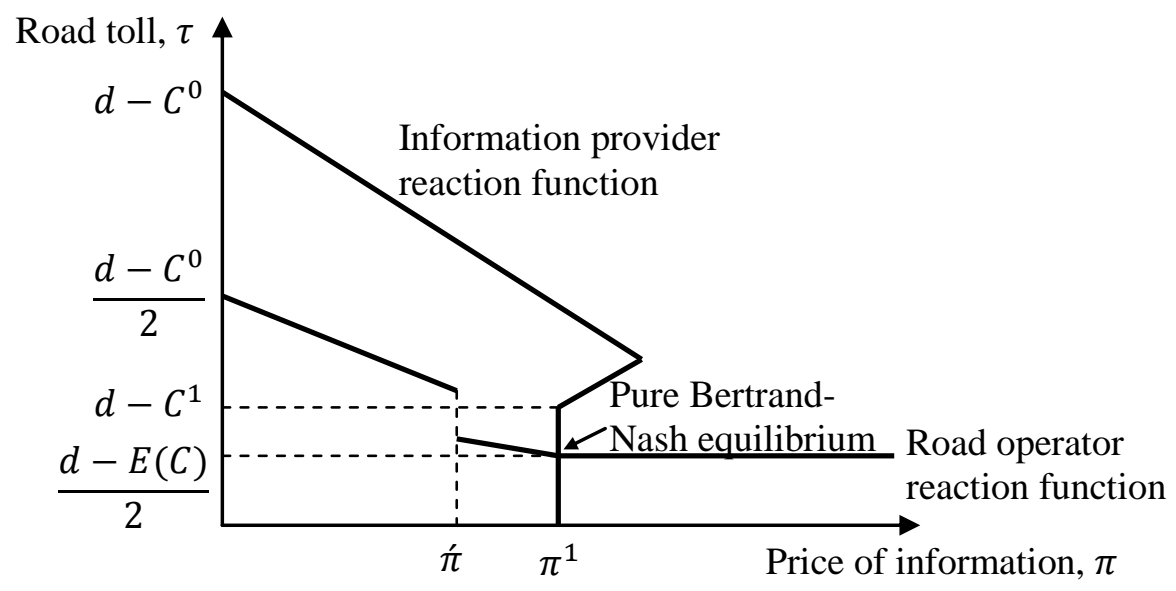

different. Most notably this function is discontinuous, which stems from the profit function not being quasi-concave, as illustrated in Figure 4. With a small change of the price of information the global maximum might change discontinuously from $\tau_{\text {high }}$ to $\tau_{l o w}$ (Rasmusen, 2006, p.97). The profit function $\Pi_{R}(\tau)$, conditional on the toll $\tau_{\text {high }}>d-C^{1}$ and $\pi \leq \pi^{1}$ is: 
$\Pi_{R}=\tau_{h i g h} \cdot\left(\frac{\left(1-p^{n}\right)\left(d-C^{0}-\tau_{h i g h}\right)}{a}-\frac{\pi}{a}\right)$

for the range of information price $\pi \in[0, \pi]$, where $\pi$ is the information price when the profit function (7) generates the same return as (6), i.e. $\Pi_{R}\left(\tau_{\text {high }}\right)=\Pi_{R}\left(\tau_{\text {low }}\right)$. There are other possible solutions of the reaction functions (including mixed Bertrand-Nash equilibria), but we leave their exposition, as they are of limited practical relevance because they require rather unrealistic parameter values.

\subsection{Welfare-maximizing second-best pricing}

Free information and toll-free roads are natural benchmark cases if one considers public information provision and road operation. The conventional goal of a public agent is the overall social welfare maximization, on both markets in our case. By setting the road toll to zero, a public road operator insures efficient marginal cost pricing of the road operation in our model, but possible distortions of monopolistic information pricing remain unaddressed. A public road operator might want to subsidize road use, so as to compensate for an excessive private information price. And conversely, the public information provider might subsidize its service, to offset possible adverse impacts from monopolistic road pricing. In this subsection we look at these two cases.

Importantly, subsidizing as a policy instrument requires some reservations. The government subsidies are funded via taxation, which itself might be welfare-distortive. In practice, the marginal effect of the subsidies should be compared with the marginal cost of public funds. We do not cover this issue here, and thus implicitly assume an existence of a welfareneutral lump-sum tax.

\subsubsection{Second-best road pricing}

When the road toll is zero, the profit-maximizing price of information is equal to the route choice benefit $\pi^{1}$. As a result, not everyone who would be informed under first-best information pricing is informed under a monopolistic one. That leads to inefficiency, as some drivers who lack information abstain from travel, while they would travel when they are 
informed. To induce a higher road use, a public road operator might subsidize drivers by decreasing the cost of travel using the state-of-nature and driver independent subsidy $\gamma>0$.

The road use subsidy does not change the profit-maximizing price of information, as this price is solely determined by the route choice benefit $\pi^{1}$, defined by equation (1). And the route choice benefit $\pi^{1}$ does not change, since the subsidy applies to both states of nature $C^{0}$ and $C^{1}$. The subsidy then makes it beneficial for some drivers with demand $E(C)>D_{j}^{T} \geq C^{0}$ to start acquiring information and make trips. These drivers will travel as long as the price they pay for information is lower than the sum of their initial consumer surplus and a subsidy, i.e. $\pi^{1}<$ $(D T-C O+\gamma) 1-p n$. Note that the road use subsidy is conditional on the actual trip, whereas the price for information is paid all the time, also when drivers stay home. The newly generated trips are welfare-enhancing, providing the consumer benefit that drivers derive from those trips is higher than the cost of travel, i.e. $D_{j}^{T}>C^{0}$.

However, there is another group of drivers who alter travel behavior due to government intervention. Some drivers, who previously travelled in the fraction $1-p^{n}$ of cases (under $\operatorname{cost} C^{0}$ only), will begin travelling always (also under cost $C^{1}$ ), as $D_{j}^{T}>C^{1}-\gamma$. This causes a welfare loss, as the consumer benefit they receive is lower than the cost of travel, i.e. $D_{j}^{T}<C^{1}$. Note that under monopolistic information pricing, the number of drivers who travel under $\operatorname{cost} C^{1}$ is optimal and any additional trips generate losses. This is true because the monopolistic information price $\pi^{1}$ is such that it does not affect the participation decision of the drivers who travel all the time (drivers with travel demand $D_{j}^{T} \geq C^{1}$ ). It is those drivers who should have been travelling under $\operatorname{cost} C^{0}$ are negatively affected by the monopolistic information pricing. Since a public road operator cannot separate these two groups, it needs to balance the welfare effects in order to achieve the highest additional welfare, while using a road subsidy as a secondbest welfare-maximizing instrument. For other drivers (i.e. in Figure 1a and 1b, the drivers to the left from $N_{a}$, and to the left from $N_{c}$ until the point $\frac{d-C^{1}+\gamma}{a}$ ) the subsidy is a pure money transfer with no behavioral and social welfare effects.

It is easy to prove that a subsidy $\gamma$ attains the highest additional welfare when it is equal to the route choice benefit $\pi^{1}$. Although subsidizing is beneficial for society, it cannot achieve the first-best outcome. When $\gamma=\pi^{1}$, there are drivers who do not travel, as the price of information is too high, i.e. $\pi^{1}>\left(D_{j}^{T}-C^{0}+\gamma\right)\left(1-p^{n}\right)$. Interestingly, due to the linearity of 
the travel demand function, the expected number of trips is the same as in the first-best scenario. But the composition of trips is different, i.e. some of those who in the first-best case should be on the road, never travel (due to the high information price), while some of those who should travel only in $1-p^{n}$ percent of cases, travel all the time (due to the subsidy).

\subsubsection{Second-best information pricing}

When the price of information is zero, the profit-maximizing road operator uses profit functions (6) and (7) to set the road toll. Although everyone is informed, not everyone who would travel in the first-best scenario is willing to do so under a monopolistic road toll. Hence, a public information provider might intervene to partly correct for this market distortion.

Consider a state-of-nature and driver independent information subsidy $\delta>0$ that is given to everyone who travels at least sometimes. Not surprisingly, information subsidy as a welfareenhancing instrument achieves the first-best outcome when $\delta$ is equal to the road toll. Predictably, the road operator responds to the subsidy by an increase of the road toll. The information subsidy matches the increased road toll until the point when the number of drivers using the road is equal to the first-best case. This setup resembles Stackelberg duopoly, where one firm is a leader (the profit-maximizing road operator) and another is a follower (welfaremaximizing information provider).

\section{Numerical simulations}

We examine nine market forms of different ownership regimes. (1) "Base case: free road without ICT." Drivers make decision based on the expectations of the cost values. (2) "Private road without ICT". A lack of externalities makes road pricing a purely welfare-distortive market element. (3) "Private road with free ICT". This is a case of a free public provision of information. If the information provider is unwilling or unable to insure excludability property of the information service, it becomes a public good. (4) "Free road with private ICT." (5) "Bertrand-Nash" pricing when both road operator and information provider are private profitmaximizing firms. (6) "First-best marginal cost pricing." (7) "Private collusion" when a single monopolist owning both road network and traffic information about it. (8) "Private road with second-best ICT subsidy." (9) "Private ICT with second-best road use subsidy." 
To analyze the welfare implications of the various road market arrangements, we use a parameterized numerical version of the model. We set the number of parallel identical routes $n=$ 2; the cost of travel without a delay is normalized to $C^{0}=1$ and the cost of travel with a delay is $C^{1}=1.5$. Probability of a delay on one route is $p=0.25$, which corresponds to one delay per 4 trips. Demand elasticity, $e$, under expected cost level, $E(C)$, is $-0.4 .^{5}$ To cast the discussion of the number of drivers, $N$, in terms of percentages of the basic equilibrium under $E(C), N$ is equal to 100 in the reference equilibrium. Sensitivity analysis in the next section will illuminate the robustness of the main findings.

The results of the baseline simulations are in Table 1. For each of the nine market forms we indicate both road toll and information price. The number of potential drivers shows the amount of drivers who would travel on the road in the low-cost state $\left(C^{0}\right)$, under the given road toll and information price. The number of expected trips either equals the number of potential drivers or is lower, because informed drivers with travel demand $C^{1}>D_{j}^{T} \geq C^{0}$ abstain from the trip in $p^{n}$ percent of time when the travel cost on all routes is $C^{1}$.

We ignore fixed cost in our model. Profit from the information provision is therefore the product of the information price and the number of potential drivers. Note that not all drivers have to be informed - a driver might use a road network without buying information. Nevertheless, our simulation results show that every potential driver will acquire information, if information technologies are available, in the ownership regimes that we consider. As a general rule, to find profit from the information provision, we have to multiply the information price by the number of drivers willing to be informed. Profit from the road operation is given by the product of the road toll and the expected number of trips.

We show consumer as well as producer surplus, the latter being the sum of information and road profits. We compute government spending on the subsidies in the last two market arrangements. Social welfare is the sum of consumer and producer surpluses minus government spending. The last row of Table 1 presents the ranking of the social welfare outcomes.

The results are more informative if one reports the relative efficiency of the market setups, $\omega$, instead of the nominal values of social welfare. Following Arnott, et al. (1991), $\omega$ is defined as:

\footnotetext{
${ }^{5}$ A long-term commuting car time elasticity in the EU is equal to -0.4 (Jong and Gunn, 2001).
} 
Table 1. Characteristics of various market arrangements based on the baseline numerical estimations

\begin{tabular}{|c|c|c|c|c|c|c|c|c|c|}
\hline Market forms & $\begin{array}{r}\text { Base case: } \\
\text { road without } \\
\text { ICT }\end{array}$ & $\begin{array}{r}\text { First-best } \\
\text { marginal } \\
\text { cost pricing }\end{array}$ & $\begin{array}{l}\text { Private road } \\
\text { without ICT }\end{array}$ & $\begin{array}{r}\text { Private road } \\
\text { with free ICT }\end{array}$ & $\begin{array}{r}\text { Free } \\
\text { road with } \\
\text { private ICT }\end{array}$ & $\begin{array}{r}\text { Bertrand- } \\
\text { Nash }\end{array}$ & $\begin{array}{r}\text { Private } \\
\text { collusion }\end{array}$ & $\begin{array}{r}\text { Private } \\
\text { road with } \\
\text { public ICT } \\
\text { subsidy } \\
\end{array}$ & $\begin{array}{r}\text { Private } \\
\text { ICT with } \\
\text { public road } \\
\text { use subsidy }\end{array}$ \\
\hline Information price & NA & FREE & NA & FREE & 0.09 & 0.09 & 0.09 & -2.94 & 0.09 \\
\hline Road toll & FREE & FREE & 1.41 & 1.45 & FREE & 1.41 & 1.36 & 2.94 & -0.09 \\
\hline Number of potential drivers & 100.00 & 104.44 & 50.00 & 52.78 & 100.89 & 50.89 & 52.56 & 104.44 & 104.22 \\
\hline Number of expected trips & 100.00 & 103.33 & 50.00 & 51.67 & 100.00 & 50.00 & 51.67 & 103.33 & 103.33 \\
\hline Information profit & NA & 0.00 & NA & 0.00 & 9.46 & 4.771 & 4.93 & 0.00 & 9.78 \\
\hline Road profit & 0.00 & 0.00 & 70.31 & 75.078 & 0.00 & 70.312 & 70.23 & 303.54 & 0.00 \\
\hline Producer surplus & 0.00 & 0.00 & 70.31 & 75.078 & 9.46 & 75.083 & 75.16 & 303.54 & 9.78 \\
\hline Consumer surplus & 140.62 & 150.42 & 35.16 & 37.80 & 140.79 & 35.32 & 37.71 & 150.42 & 150.32 \\
\hline Government spending & 0.00 & 0.00 & 0.00 & 0.00 & 0.00 & 0.00 & 0.00 & 303.54 & 9.69 \\
\hline Social welfare & 140.62 & 150.42 & 105.47 & 112.88 & 150.25 & 110.41 & 112.87 & 150.42 & 150.41 \\
\hline Relative efficiency, $\omega$ & 0 & 1 & -3.59 & -2.833 & 0.98 & -3.09 & -2.835 & 1 & 0.999 \\
\hline Welfare rank & 5 & 1 & 9 & 6 & 4 & 8 & 7 & 1 & 3 \\
\hline
\end{tabular}


$\omega_{i}=\frac{\text { welfare }_{i}-\text { welfare }_{\text {ref }}}{\text { welfare }_{f b}-\text { welfare }_{\text {ref }}}$

where $\omega_{i}$ is the relative efficiency of the market setup $i$, welfare ${ }_{i}$ is the social welfare that

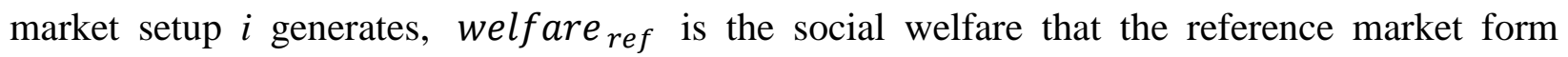
produces (in our case it is "free road, no ICT" market) and welfare f $_{b}$ is the social welfare under first-best conditions (i.e. marginal cost pricing "free road, free ICT"). Hence, $\omega$ equals zero in the reference equilibrium and equals one for the first-best market arrangement. A positive $\omega$ indicates that the market setup performs better than the reference one. A negative $\omega$ indicates a reduction in social welfare as compared to the reference case.

Predictably, a market with a marginal cost pricing ("free road, free ICT") generates the highest social welfare. The pool of potential drivers is the largest of all cases we consider. The number of expected trips is lower than the number of potential drivers, because in 6.25 percent of time drivers with travel demand $C^{1}>D_{j}^{T} \geq C^{0}$ do not travel while being informed.

A market with second-best information subsidies and private roads ("private road, ICT subsidy") mimics the first-best welfare outcome. The information subsidy exactly compensates for the road toll, and hence fully covers the profit of the private road operator. Prices allow the same number of drivers and expected trips as in the first-best marginal cost pricing arrangement.

A market with second-best road use subsidies and private information ("road subsidy, private ICT") slightly lags behind the first-best. The road use subsidy, $\gamma$, equals the information price, and almost all information profit is financed by subsidies. Note that producer profit is a bit larger than government spending, as drivers always buy information, but do not always travel and thus do not always receive subsidy. Hence, drivers have to pay the difference from their own money. Monopolistic information price prevents some drivers with willingness to pay for travel which is higher than $C^{0}$ to make trips, therefore the number of potential drivers is lower than the first-best. As discussed before, due to the linearity of the travel demand function, the number of expected trips is the same as in the first-best.

An untolled road network with private information provision ("free road, private ICT") yields a social welfare close to the first-best market form. It is interesting to note that monopolistic information pricing has only a very small distortive impact on social welfare. In fact, the social welfare difference between the first-best "free road, free ICT" market and "free 
road, private ICT" market is negligible in our parameterization. While private information decreases the consumer surplus, the decline is to a large extent offset by the producer surplus rise. The profit-maximizing information price is such that the resulting social welfare deadweight loss is rather small (in Figure 1c, the deadweight loss is the area below the demand curve to the right from $N_{c}$ ).

Comparison of the "free road, private ICT" market with "free road, no ICT" offers a nice illustration of the private ICT effect. The social welfare is lower in the market without information. Still, a lack of the information does not change the expected road use, while the number of potential drivers drops slightly. The consumer surplus decreases very little. In fact, most of the social benefits that information generates are skimmed off by the private information provider. Only drivers with travel demand $C^{1}>D_{j}^{T} \geq C^{0}$ gain an additional consumer surplus. The consumer surplus gains of those drivers with the higher travel demand, equal to the route choice benefit, is fully internalized into the information provider's profit.

The non-existence of congestion in our model makes a positive road toll welfaredistorting. The private road with free information is ranked the $6^{\text {th }}$ out of the 9 market forms we consider. The social welfare is substantially lower in comparison to the above mentioned markets.

Somewhat surprisingly, the $7^{\text {th }}$ market arrangement in our ranking is the private collusion scenario, when one profit-maximizing firm controls both an operation of the road network and a provision of the traffic information about it. The Bertrand-Nash case performs worse in terms of social welfare. This effect resembles the double marginalization (originally due to Cournot, see an exposition in, for instance, Weyl, 2008), when a single monopolist charges a lower overall mark-up, compared to the joint effect of two separate, complementary firms mark-ups. But our case is slightly different.

To remind, double-marginalization is the overpricing (above a monopoly price) which occurs when two complementary firms are setting prices independently with the goal to maximize their own profits. The sum of the two prices is higher than the price that a single monopolist controlling both firms would charge, as the independent firms do not take into account the negative effects of their prices on the profit of the complementary firm. Doublemarginalization might occur when an upstream monopolist provides supply to a downstream monopolist, which, in turn, sells the product to the final users. Otherwise, double-marginalization 
might also arise when two monopolists provide complementary products directly to the final user. The case of the road network and traffic information resembles the latter alternative, although it has a distinction.

An important aspect of double-marginalization is the strict complementarity of the products, which road and traffic information do not have. Road and traffic information are asymmetric products, as a driver can use the road without being informed, while it makes no sense to be informed without making any trips. Drivers choose voluntarily, depending on the information price, whether to access information or not. In case of standard doublemarginalization the two products should be acquired together and only the joint price determines the demand level which clears the market. In turn, in our case the price structure, i.e. shares of the road toll and information price in the overall monetary travel cost, determines the demand level as well. Although not a standard case of double-marginalization, private road market with private ICT reveals similar phenomenon - independent road operation and information provision pricing leads to an overall mark-ups that exceeds the monopoly mark-up. That, consequently, leads to the social welfare level below that of a single monopoly.

Referring back to the simulation results, the sum of the equilibrium information price and a road toll under a collusion scenario is equal to the equilibrium private road toll with free information ("private road, free ICT"). ${ }^{6}$ Although, the monetary costs are equal in those two cases, the cost composition is different. That leads to the difference in the number of potential drivers and, consequently, in the welfare levels. ${ }^{7}$ A monopolist attracts more potential drivers by setting a lower road toll. It trades off the profit from road toll with the profit from information provision. While some profit from the road operation will be lost, revenue from information provision does compensate for that loss.

The least preferable market form from the social perspective is the private road without information. There are few potential drivers and the consumer surplus is the lowest of all. Note that the expected number of trips, the road toll and the profit of the road operator are the same as in the Bertrand-Nash oligopoly market.

\footnotetext{
${ }^{6}$ The equality holds true under specific parameter values, due to travel demand linearity.

${ }^{7}$ Note that the expected number of trips is the same.
} 


\section{Sensitivity analysis}

We now present a sensitivity analysis to check the robustness of the numerical results. We focus on the relative performance of the various road market arrangements in terms of social welfare as a function of two important model parameters. At first we look at the effect caused by the variation of the probability $p$. This variation shows the influence of the unreliability of the road network on social welfare. Then we vary the travel demand elasticity $e$.

Ideally, we want to test the effect of one parameter change on the simulation results, keeping everything else the same. The initial reference market is the "free road, no ICT" case. By keeping the stochastic cost levels $\left(C^{0}\right.$ and $\left.C^{1}\right)$ constant, an increase in incident probability $p$ causes the upward shift of the expected cost. Thus, the effect of unreliability is combined with and augmented by the variation in the expected travel cost. To keep the initial equilibrium the same (a number of potential drivers, elasticity level) we keep the expected cost constant while adjusting $p$. When we change probability, we move the stochastic cost levels simultaneously around the constant expected cost $E(C)$. We keep the difference $C^{1}-C^{0}$ constant.

Figures 9 and 10 depict relative efficiency of the various markets in terms of $\omega$ 's as a function of probability $p$. Note that the ranking of the welfare outcomes does not changes, which

Figure 9. Relative efficiency of the market setups as a function of the delay probability $p$, under constant expected cost $E(C)$

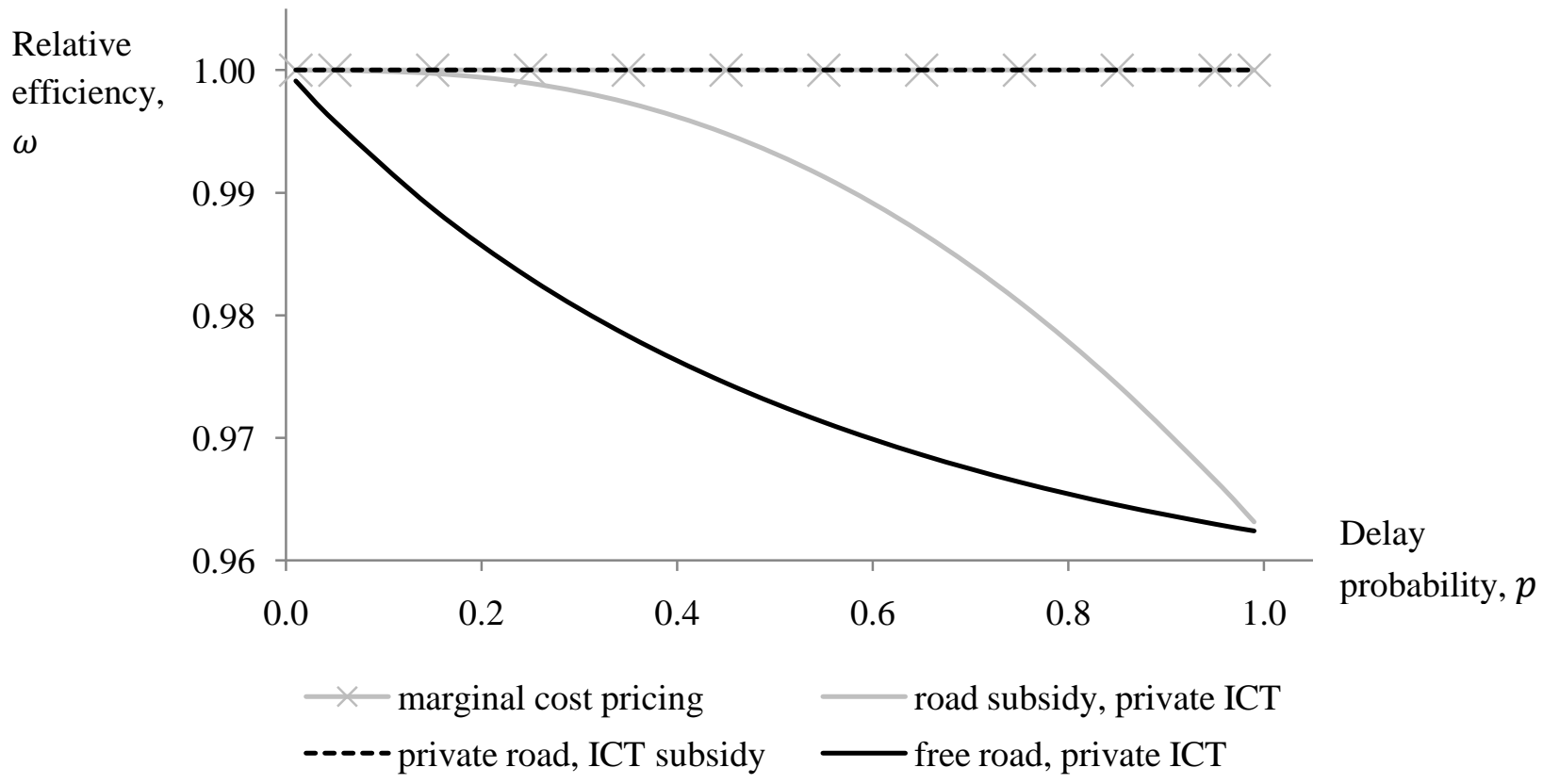


suggests the robustness of our findings. Figure 9 shows that "road subsidy, private ICT" market does well in comparison to the first-best. However, some drivers abstain from the trip due to the monopolistic information price. The relative efficiency decline is reflected in Figure 9 by a downward sloping $\omega$ function. Note that the road subsidy compensates for some part of the information price inefficiency. When the chance of a delay is low, the number of drivers affected by the monopolistic information price is very small (in Figure 1b, these are drivers to the right from $N_{c}$ ). But with an increase of $p$ the number of abstaining drivers is getting higher, which reduces welfare. The lack of the road use subsidies makes "free road, private ICT" market to perform worse than the above mentioned ones, because there is no mechanism to compensate for the monopolistic information price.

When the probability of a delay is very low or very high, the price of information is small. Everyone knows that a travel cost most of the time is cheap ( $p$ low) or expensive ( $p$ high), so there is little reason to pay a lot for information. When the probability of a delay approaches 50 percent, the value of the information gets higher. The monopolistic pricing rule follows equation (1), i.e. $(1.5-1)\left(p-p^{2}\right)$, which reaches the highest value at $p=0.5$. Because the information price is very small at the extreme $p$ values, the road use subsidy, which equals the information price, does not notably affect the market performances. Thus, the performances of

Figure 10. Relative efficiency of the market setups as a function of the delay probability $p$, under constant expected cost $E(C)$

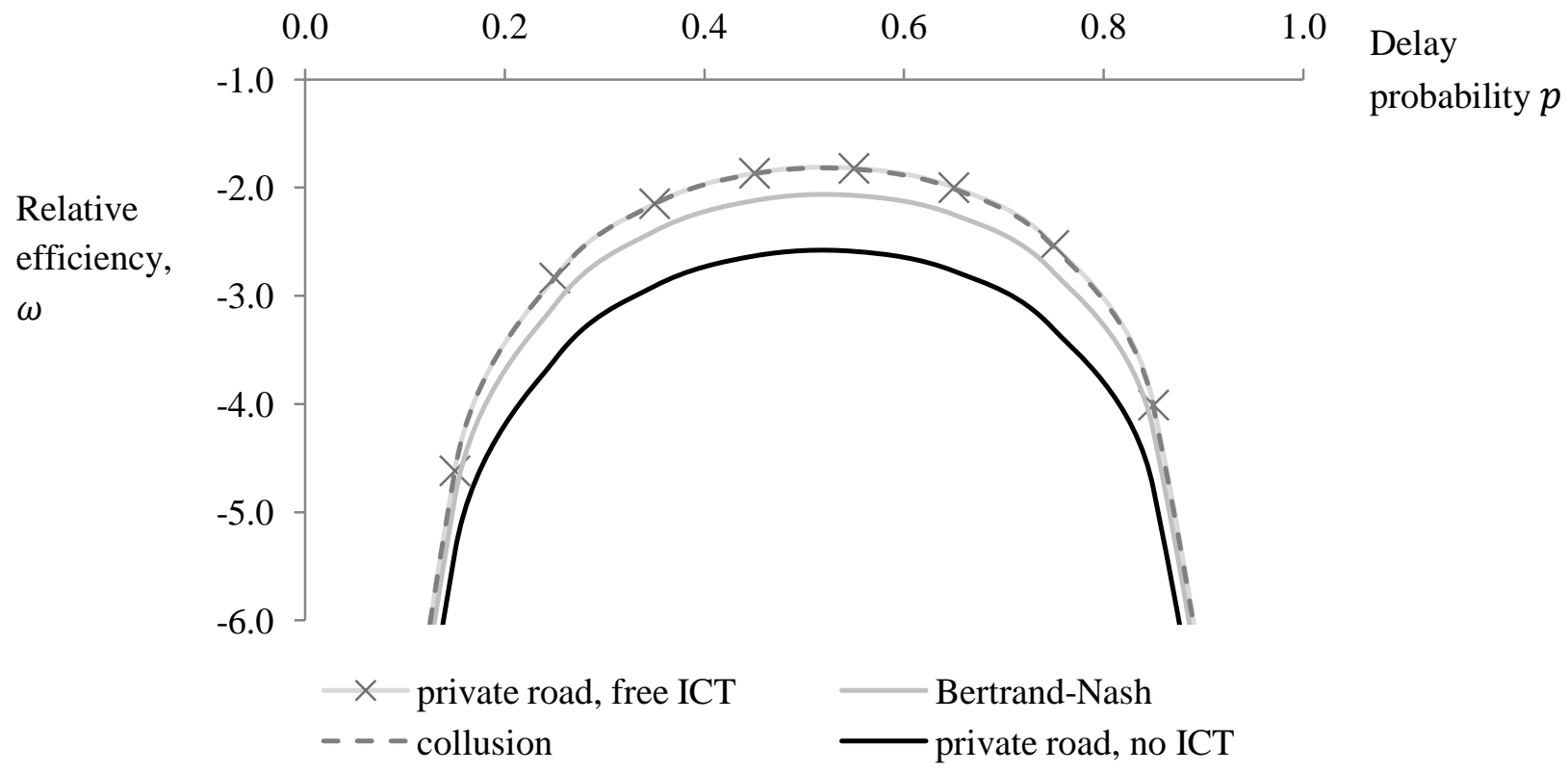


the two markets converge.

Figure 10 shows relative efficiencies of the other four markets. At extreme $p$ values, when information has a relatively small impact on a market, the welfare levels are converging. All of the markets include a positive road pricing, thus, an absence of congestion results in welfare distortion as compared to the reference case "free road, no ICT", making $\omega$ 's negative. The shapes of all four relative efficiency functions are alike. In comparison to the first-best market all markets do relatively well when $p$ is around 50 percent.

Figures 11 and 12 show the relative efficiency of the markets as a function of travel demand elasticity. We obtain varying base-case elasticities by tilting the travel demand function around its intersection point with the expected cost function in the base equilibrium. Elasticities close to zero result in a very steep travel demand function. That makes the number of drivers willing to travel both under $C^{0}$ and $C^{1}$ costs relatively larger, and their consumer surplus bigger. There are relatively few drivers who might consider staying home when being informed when the cost of travel is $C^{1}$. When elasticity increases (in absolute terms), the demand function gets flatter. The consumer surplus shrinks, and more drivers might enjoy also a participation benefit of information, besides a route choice benefit, making information more valuable. The relative number of drivers who travel only when being informed increases with the rise of elasticity.

For the main numerical simulations we assumed that the travel demand elasticity is -0.4 . The variation of elasticities from -0.1 to -1.3 does not change the ranking of the market arrangements. As this is the empirically relevant interval (Jong and Gunn, 2001), the baseline ranking again appears to be robust. Figure 11 shows that markets with either road use or information public subsidies perform close to the first-best outcome. In the "free road, private ICT" market, with an increase of the absolute travel demand elasticity a private information provider sets higher monopolistic mark-up, as information becomes more valuable. Although, that decreases the market relative efficiency, the ranking is preserved.

Figure 12 shows that all $\omega$ 's rise when demand becomes more elastic (except for "free road, no ICT" market which is by default always zero). The flatter the travel demand function, the larger is the share of drivers who would travel only when informed. ICT allows to attract those drivers to the road market, making social welfare, and hence omega, larger. In conclusion, the ranking is quite robust, strictly so in the empirically relevant range, and otherwise the difference is small. 
Figure 11. Relative efficiency of the market setups as a function of travel demand elasticity $e$

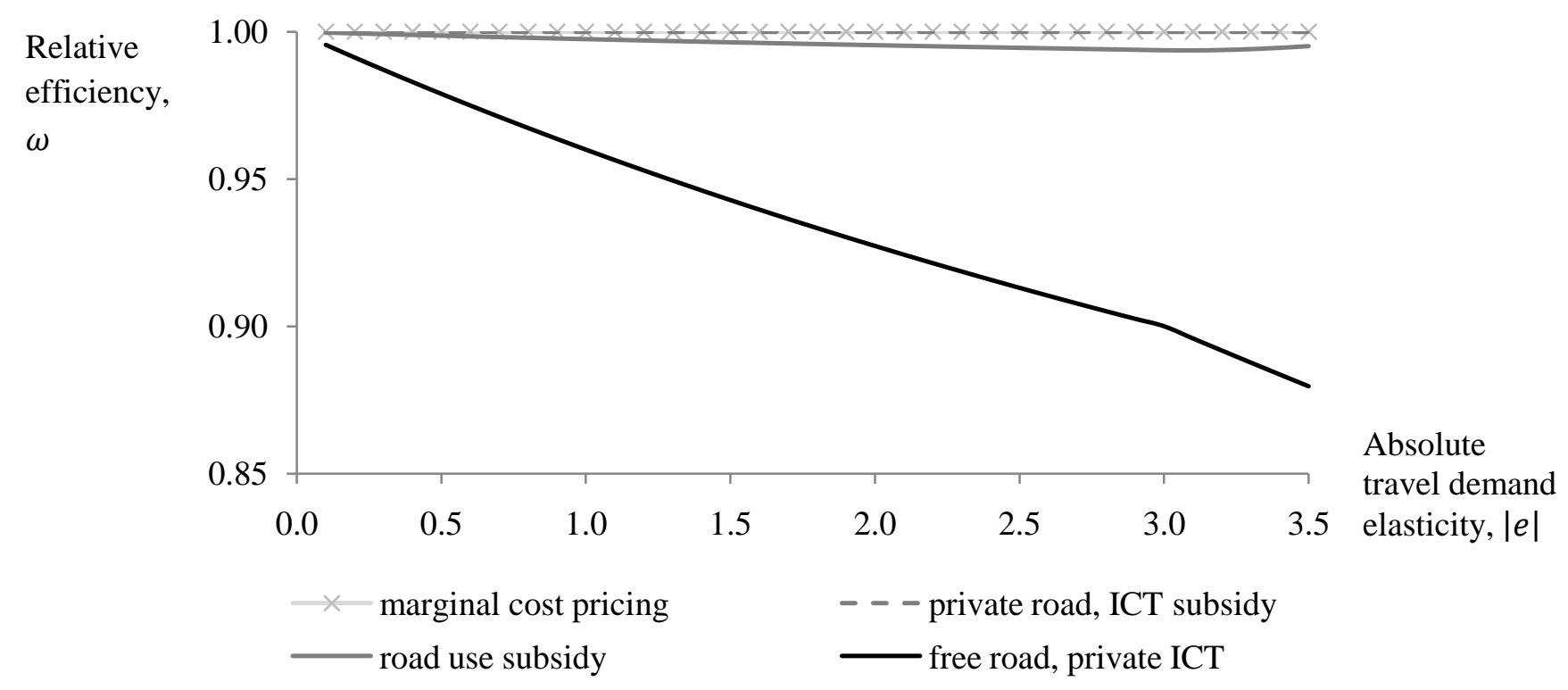

Figure 12. Relative efficiency of the market setups as a function of travel demand elasticity $e$

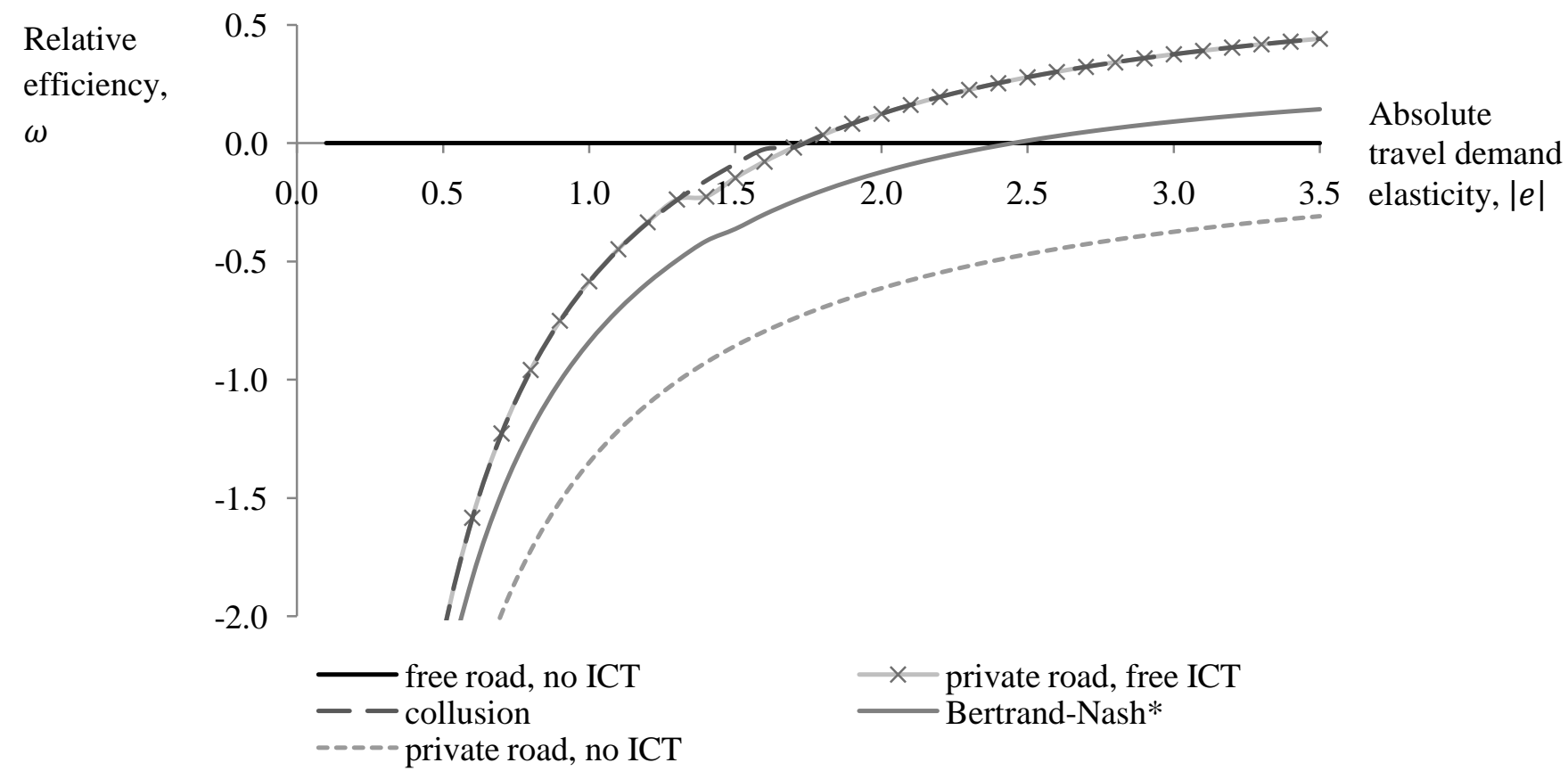

Note: * for elasticities larger than $|-1.5|$ we report expected omegas of the mixed Bertrand-Nash equilibria. 


\section{Summary and conclusions}

We study the welfare effects of information provision in the context of a market where potential drivers are facing a choice of whether to make a trip and if so, which route to take. Due to the stochastic travel time and hence cost, they are willing to pay for information about the actual travel time. From a travel demand-supply setup, we derived the endogenous demand for information. We showed the profit and welfare maximizing pricing strategies of both a road operator and an information provider, while accounting for the interdependency of those strategies. Using numerical simulations we examined nine market forms with different ownership regimes and compared the social welfare they generate. Sensitivity analysis proved the robustness of the main findings.

The analysis sheds light on some welfare implications of information provision. Interestingly, it does not matter much whether the information is provided by a public or a private company. Because of the kinked shape of the endogenous demand for information, the dead-weight loss created due to the monopolistic mark-up is negligible. The dead-weight loss in the transport market is even smaller if the government can compensate for the inefficient information pricing with a public road use subsidy. In case the road operator is a profit-seeking firm, the Bertrand-Nash price equilibrium yields a lower social welfare in the market with private information provider, as compared to the market where information is free. But the difference in social welfares is not large. The main pricing strategy of the private information firm is to skim off the consumer surplus of those drivers who will travel irrespective of the travel costs, which requires an equalization of the information price to the route choice benefit. Essentially, the price mark-up hardly affects overall social welfare, but only redistributes some part of welfare from consumers to information monopolist. There are relatively few drivers who are left outside the market due to monopolistic information pricing.

Secondly, the expected road use will remain the same in our linear model if a private information provider starts operating in the market. Most of the drivers will only change their route choice behavior and not forego trips altogether, as even the largest travel cost they might incur is lower than their willingness to pay for travel. Some informed drivers, nevertheless, will start abstaining from the trips when the travel costs are high on every road, as they will be better off by staying home than travelling. However, the number of abstained trips will be exactly offset by drivers who will start travelling when informed, conditional on the monopolistic price 
of information. Interesting to note, a private road operator might not even notice the entry of the private information provider into the transport market. That is, the Bertrand-Nash price equilibrium in the "private road, private information" market might lead to the same expected road use, road toll and road operator's profit as in the "private road, no information" market.

Finally, it seems that private collusion is a better market arrangement than a market with independent profit-maximizing road and information operators. Traffic information is not a pure complementary product to road use. Nevertheless, similar to the double-marginalization case, the mark-up of a single monopolist is lower than the sum of two independent mark-ups. That leads to a higher social welfare under a monopolistic market form than under two separate firms. There appears, therefore, the little reason to prevent private road operators from offering paid information on traffic conditions on their roads. It is not true that this raises their market power and therefore induces higher prices than a split firm would charge.

This paper is the first one to consider industrial organizational aspects of a market with a single core supplier (the road operator in our example), information provider, and end users. We showed how welfare effects of information introduction might vary depending on the market arrangement. There are, of course, several possible extensions one might consider to incorporate into the analysis. It seems natural to contrast the findings in this model with those in a model with congestion. It would also be interesting to relax the assumption of homogeneity of drivers with respect to value of time. One can expand the model by an introduction of sequential routes or a toll-free public route as an alternative to the private routes. Furthermore, a probability of delay and a cost of travel might be set as a function of a road operator's investment. More research is therefore still needed to obtain a more comprehensive view of the effects of information provision on social welfare.

\section{References}

Arnott, R., A. de Palma and R. Lindsey. 1991. Does providing information to drivers reduce traffic congestion? Transportation Research Part A: General 25(5): 309-318.

de Jong, G. and H. Gunn. 2001. Recent evidence on car cost and time elasticities of travel demand in Europe. Journal of Transport Economics and Policy 35(2): 137-160.

de Palma, A. and R. Lindsey. 1998. Information and usage of congestible facilities under different pricing regimes. The Canadian Journal of Economics 31(3): 666-692. 
de Palma, A. and N. Picard. 2006. Equilibria and information provision in risky networks with risk-averse drivers. Transportation Science 40(4): 393-408.

Emmerink, R.H.M., E.T. Verhoef, P. Nijkamp, and P. Rietveld. 1996. Information provision in road transport with elastic demand: A welfare economic approach. Journal of Transport Economics and Policy 30(2): 117-136

Emmerink, R.H.M., E.T. Verhoef, P. Nijkamp, and P. Rietveld. 1998. Information effects in transport with stochastic capacity and uncertainty costs. International Economic Review 39(1): 89-110.

Fernández L., E.J., J. de Cea Ch, and G. Germán Valverde. 2009. Effect of advanced traveler information systems and road pricing in a network with non-recurrent congestion. Transportation Research Part A: Policy and Practice 43(5): 481-499.

Kehoe, M. R. 1996. Quality uncertainty and price in monopoly markets. The Journal of Industrial Economics 44(1): 25-32.

Kihlstrom, R. 1974. A Bayesian model of demand for information about product quality. International Economic Review 15(1): 99-118.

Lizzeri, A. 1999. Information revelation and certification intermediaries. The RAND Journal of Economics 30(2): 214-231.

Rasmusen, E. 2006. Games and information: an introduction to game theory. Wiley-Blackwell, London.

Salop, S. 1977. The noisy monopolist: imperfect information, price dispersion and price discrimination. The Review of Economic Studies 44(3): 393-406.

Small, K. and E.T. Verhoef. 2007. The economics of urban transportation. Routledge, London.

Stigler, G. J. 1961. The economics of information. The Journal of Political Economy 69(3): 213-225.

Stiglitz, J. E. 2000. The contributions of the economics of information to twentieth century economics. Quarterly Journal of Economics 115(4): 1441-1478.

Verhoef, E.T., R.H.M. Emmerink, P. Nijkamp, and P. Rietveld. 1996. Information provision, flat and fine congestion tolling and the efficiency of road usage. Regional Science and Urban Economics 26(5): 505-529.

Weyl, E.G. 2008. Double marginalization in two-sided markets. Working paper Harvard University.

Wolfstetter, E. 1999. Topics in microeconomics: Industrial organization, auctions, and incentives. Cambridge University Press, Cambridge.

Yang, H. 1999. Evaluating the benefits of a combined route guidance and road pricing system in a traffic network with recurrent congestion. Transportation 26(3): 299-322.

Zhang, R. and E. T. Verhoef. 2006. A monopolistic market for advanced traveler information systems and road use efficiency. Transportation Research Part A: Policy and Practice 40(5): 424-443. 